\title{
Lara Amat y León, Joan (ed.). La ciudadanía y lo político. Ciudadanía y crisis de la democracia liberal en un mundo en transformación. Lima: ONPE, 2020.
}

\author{
Martí Colom Nicolau \\ Universitat de Barcelona
}

Fecha de recepción 26/10/2021 I De publicación: 23/12/2021

Ya lo dijo Gramsci, vivimos unos tiempos en los que lo viejo va muriendo, pero lo nuevo no termina de llegar. Entre tanto, asistimos al aumento y enquistamiento de las desigualdades -económicas, culturales, de género...- y a un auge de los populismos, mientras la grave crisis climática que se cierne sobre nosotros desencadena y favorece migraciones masivas y violaciones de derechos humanos.

En esta encrucijada histórica, del lado de lo viejo tenemos un liberalismo de inspiración decimonónica y su vástago neo. Ambos paradigmas ofrecen muestras de agotamiento, tal como ponen de relieve las crisis de confianza y legitimidad que afrontan tanto las formas políticas representativas de lo que tradicionalmente se ha llamado democracia liberal, como las recetas económicas neoliberales que se han ofrecido como único remedio a las grandes crisis capitalistas.

Por su parte, lo nuevo no termina de llegar. Después del hundimiento del bloque soviético y del triunfo del neoliberalismo a partir de la década de los setenta del siglo XX, lo que tradicionalmente se había llamado la izquierda, y, en general, todo el pensamiento de cariz emancipador, se encuentra sumido en un estado de desorientación. Habiendo mostrado sus limitaciones los grandes sistemas sobre los que se habían fundado las promesas de justicia social en el pasado, existe un estado de desconcierto, sin que esté claro qué camino es el que conducirá a la salida de este laberinto.

Ante este escenario, entre los herederos de esa izquierda se pueden identificar dos tendencias: una apuesta por hacer borrón y cuenta nueva, construyendo nuevos conceptos y categorías con los que enfrentarse a la realidad; la otra opta por ahondar en los fundamentos de la tradición emancipadora ilustrada y republicana, entendiendo que lo necesario es, de una vez por todas, actualizar todas sus potencialidades liberadoras. En términos generales, este libro emprende el segundo camino. 
La ciudadanía y lo político. Ciudadanía y crisis de la democracia liberal en un mundo en transformación es fruto de la colaboración entre el proyecto de investigación Ciudadanía y Crisis de la Democracia Liberal en un Mundo en Transformación de la Universidad Nacional Mayor de San Marcos, y la Oficina Nacional de Procesos Electorales del Perú. Se trata de una obra colectiva que incluye trabajos de nada menos que treinta autores de ambos lados del Atlántico. Desde un enfoque multidisciplinar, que abarca desde la filosofía y el derecho hasta el urbanismo y el marketing, pasando por la sociología, la economía o la ciencia política, ofrece una aproximación transversal a los principales desafíos que las carencias del paradigma liberal plantean en nuestras sociedades. Se debe aplaudir la tarea organizativa e institucional del editor de esta obra, Joan Lara Amat y León, que ha conseguido implicar a un nutrido grupo de investigadores de universidades peruanas y españolas en un proyecto común, y que ha conseguido que el producto de esta empresa vea la luz en forma de libro.

La obra contiene artículos que adoptan tres enfoques complementarios: de descripción y análisis de la realidad, de crítica de esta realidad, y de proposición de alternativas. Estos trabajos vienen organizados en cuatro partes. La primera parte agrupa los artículos que versan sobre la experiencia política en sus contornos más generales. La segunda parte, en línea con la voluntad de actualizar esa tradición emancipadora, está dedicada a repensar la categoría de ciudadanía, tanto para valorar su idoneidad para pensar el presente, como para proponer las posibles modificaciones conceptuales que ello pueda requerir. En este sentido destacan los trabajos de Antonio Peña Jumpa y Pol Cuadros Aguilera, que ponen la noción de ciudadanía en relación con la vivencia comunal aimara y con el cuerpo humano, respectivamente. La tercera parte es la más extensa, y se dedica a analizar las múltiples dimensiones de la crisis que hoy en día atraviesa la democracia liberal. El trabajo de Héctor Silveira Gorski, con su insistencia en la necesidad de reforzar lo común desde un poder ciudadano independiente de los poderes privados y estatales, constituye un buen ejemplo de propuesta de solución frente a esta crisis de la democracia liberal. Por último, la cuarta parte se ocupa de ciertas transformaciones especialmente acuciantes que dicha crisis pone sobre la mesa. Por ejemplo, la que concierne al modelo económico capitalista, que Henry Jishar Velarde García desgrana en su artículo; o la que atañe a la reconfiguración del tablero geopolítico mundial que el surgimiento de los BRICS puede propiciar, examinada por Francesco Petrone.

Una de las principales virtudes de este libro es la de poner en diálogo la realidad de América Latina, y en concreto, la del Perú, con la realidad europea y, en concreto, española. Tal como Víctor Méndez 
Baiges explicita en su contribución al libro, en el contexto de un mundo globalizado e hiperconectado tendemos a girar siempre la cabeza hacia los países anglosajones. Leemos a sus autores e importamos sus teorías y esquemas para enjuiciar nuestras realidades. Y, pese a lo fructífero que ello pueda resultar -pues no debemos olvidar la naturaleza universal de la razón-, el hecho es que los supuestos culturales, sociales, económicos etcétera sobre los que esos autores construyen su pensamiento a menudo divergen notablemente de los nuestros. Es de agradecer que esta obra, desde una perspectiva situada - pero sin caer en el relativismo o el particularismo-, preste atención a lo característico de la realidad iberoamericana, que viene definido, en gran medida, por su historia colonial compartida, tal como ilustra el artículo de Carlos Amat y León Chávez.

Pese a lo heterogéneo del libro -consustancial, por otra parte, a la naturaleza colectiva de su autoría-, puede identificarse una tesis de fondo que es compartida, a grosso modo, por sus autores, a saber, que el paradigma liberal es insatisfactorio porque desatiende las condiciones de posibilidad de la democracia. De la democracia entendida no como sinónimo de gobierno representativo, en que de vez en cuanto el ciudadano es llamado a introducir un voto en una urna, sino entendida como la organización igualitaria del poder y de la libertad, donde cada ciudadano, con independencia de factores moralmente arbitrarios, vale lo mismo que los demás, y donde el acceso a cargos de responsabilidad política no se encuentra vetado, de facto o de iure, a grandes capas de la población. Esta tesis de fondo se puede identificar con especial claridad, por ejemplo, en los artículos de Willian Hernández Hurtado y Nemrod Carrasco Nicola, que insisten en la necesidad de superar esa mirada superficial liberal que desatiende las causas sociales y políticas responsables de las estructuras de poder vigentes.

De una parte, se desatienden las condiciones materiales del ejercicio de la libertad y de los derechos. En el contexto de una economía capitalista, con la desigual distribución de la riqueza que le es propia, esta desatención a la posición material de partida de los ciudadanos resulta, de facto, en la consagración de privilegios para los poderosos, esto es, los propietarios. Son varios los artículos que subrayan la idea de que la previsión constitucional de un catálogo de derechos fundamentales más o menos amplio, tal como es propio en las tradiciones jurídicas iberoamericanas, queda en papel mojado si no se dan las condiciones materiales para el ejercicio efectivo de tales derechos. En esta dirección apunta el artículo de MarcAbraham Puig Hernández, que aboga por la superación de la concepción liberal de la libertad de conciencia. En la misma línea, Tomeu Sales Gelabert indica que, si bien el reconocimiento legal de derechos laborales es importante, el grado de disfrute de tales derechos queda muy limitado si la 
subsistencia de uno depende del trabajo reproductivo o asalariado. En el mismo sentido, Lesly Katerine Hernandez Huaman explica que reconocer, con carácter universal, el derecho de sufragio en una sociedad donde la riqueza se encuentra concentrada en muy pocas manos - con la traslación que ello tiene en el ámbito de la publicidad política-, no es suficiente para garantizar unos resultados electorales libres. Así mismo, Franklin Cornejo Urbina llama la atención sobre el hecho que, en un país con un acceso a la información muy desigual, y con unos medios de comunicación concentrados en manos del poder privado, la libertad de prensa, de opinión y de expresión no están efectivamente garantizadas solo con recogerlas en un texto constitucional. Gregory Pek Bardales Pereyra recalca que en este contexto el potencial emancipador de los derechos y libertades está limitado, y no podrá desarrollarse en toda su radicalidad mientras no se supere esta concepción liberal.

De otra parte, desde el liberalismo también se ignora las cualidades que los ciudadanos deben tener para que la democracia sea viable. Queriendo acomodar a las plurales concepciones del bien que, en un mundo globalizado, conviven en un mismo estado, el liberalismo desvincula la cuestión de la justicia de la de lo bueno. En contra del criterio de Joan Antón Mellón y Elisenda Antón Carbonell, que apuestan por el interculturalismo, el liberalismo opta por el multiculturalismo como modelo de gestión de la diversidad. En qué consista una vida buena es cosa que se deja en manos de cada persona, concebida en términos individualistas. En este paradigma, lo justo se reviste de un carácter formal, moralmente neutro, y se da el protagonismo al diseño institucional, con la creencia que unas instituciones correctamente diseñadas son condición suficiente para una sociedad funcional y justa.

La obra que reseñamos no ignora la importancia del elemento institucional. De hecho, artículos como el de Gerson Julcarima Álvarez exploran los efectos que el diseño institucional del gobierno semipresidencialista peruano tiene sobre la gobernabilidad democrática del país, mientras que el de Edson Villantoy Gómez consiste en un estudio comparativo de la transición e instituciones en el Perú y México democráticos. Sin embargo, tal como explica Rosa Isabel Sánchez Benites, un buen diseño institucional, legal y constitucional no será suficiente para engendrar una sociedad democrática sin una ciudadanía activa. Y para que la ciudadanía devenga activa, una cierta configuración del carácter es necesaria. Ello nos conduce a la necesidad de cultivar la virtud cívica.

Si hablamos de virtud cívica, como ya se sabía en la antigua Atenas de la paideia, la educación juega un papel fundamental. La virtud, en cuanto disposición de una persona a actuar correctamente, es un hábito que se adquiere por medio de la práctica. Por lo tanto, para tener ciudadanos virtuosos, deberá 
promoverse el actuar conforme a la virtud cívica. Y esa tarea no debe descansar solamente en la educación stricto sensu, sino también en las leyes, y aún en el diseño del espacio público, tal como indica Karen Sayuri Susuki Ríos, poniendo de relieve la conexión entre urbanismo, comunidad y democracia.

Un rasgo inherente al cultivo de dicha virtud es la promoción del espíritu crítico y la preocupación por los asuntos públicos entre la ciudadanía. La voluntad del libro de fomentar esta virtud se hace patente desde la introducción, cuando se insiste en que la superación de la crisis de la democracia liberal debe pasar aportar herramientas intelectuales a los ciudadanos, pues una ciudadanía formada y crítica es condición de posibilidad del refuerzo de la calidad de la democracia. Ello es aún más cierto para países con una tradición democrática poco enraizada, como es el caso del Perú que Marté Sánchez Villagómez describe en su artículo sobre la violencia en las elecciones municipales de la amazonia peruana.

Un riesgo de este tipo de enfoques es el de incurrir en un cierto voluntarismo, o en una confianza excesiva en el poder transformador de la educación, en este caso cívica. Sin embargo, y a pesar de que son muchos los autores que insisten en la importancia de desarrollar virtudes cívicas entre los ciudadanos, artículos como el de Miguel Ángel Polo Santillán remarcan, precisamente, que para lidiar con problemas multicausales no se puede fiar todo a una sola carta.

La academia tiene una importante responsabilidad en esta tarea de educación cívica, y el proyecto Ciudadanía y Crisis de la Democracia Liberal en un Mundo en Transformación no la rehúye. En la introducción ya se insiste en la necesidad de acercar la reflexión universitaria a los problemas de la sociedad, y en la pertinencia de ofrecer estas respuestas en unos términos que, sin renunciar al rigor académico, la hagan comprensible a sus destinatarios. La pluralidad de estilos y enfoques que incluye este libro podría considerarse un obstáculo frente a la pretensión de democratizar el acceso al conocimiento producido, pues aumenta el riesgo de confusión en el lector no especializado, que no tiene porqué conocer las tradiciones y presupuestos de los que parten los distintos análisis, críticas y propuestas. Sin embargo, dicha heterogeneidad se mantiene en niveles más que aceptables, y ayuda a iluminar los distintos contornos de problemas de naturaleza compleja y poliédrica.

La necesidad de promover la virtud ciudadana hace patente que no es tan fácil separar las consideraciones sobre la justicia de las consideraciones sobre lo bueno. Ahora bien, pese a asumir dicha conclusión, en el libro no se cae en el extremo de prescribir la recuperación de una comunidad fundamentalista y cerrada con una concepción cosmovisiva única de lo bueno. Son prueba de ello artículos como el de Arturo Lucas 
Cabello, que insisten en la importancia de actualizar el concepto lockeano de tolerancia y ampliar su alcance para garantizar su eficacia en las sociedades diversas de nuestro tiempo, o el de Norbert Bilbeny, quien insiste en la necesidad de evitar las tendencias uniformadoras que históricamente se han ligado al concepto de ciudadanía, abogando por reforzar el carácter pluralista de nuestras democracias, en vistas a habilitarlas para encarar los retos que las heterogéneas sociedades actuales plantean.

Uno de los productos paradigmáticos de las carencias del liberalismo que más preocupa a los autores de este libro es la corrupción y la violencia política. El diagnóstico establece que, si bien cierto grado de corrupción es atribuible a deficiencias en el diseño institucional y a comportamientos fraudulentos de individuos concretos, cuando esta corrupción alcanza ciertos umbrales de gravedad, deviene el síntoma visible de una enfermedad que afecta a toda la sociedad. Las causas de este mal pueden encontrarse en las fallas del liberalismo hasta ahora señaladas. De una parte, las grandes desigualdades erosionan en el ciudadano el sentimiento de pertenencia a la comunidad. Si a ello sumamos la desatención de la virtud cívica -nos advierte Miguel Ángel Nación Pantigoso-, el resultado son sociedades atomizadas, donde no existe la vida en común, y cuyos miembros no conciben la existencia de unos intereses colectivos que trasciendan su interés egoísta particular. Tal como denuncia Jaime Villanueva Barreto, quién alcanza cierta cuota de poder y de responsabilidad, ya sea política o económica, tiende a concebirla en términos patrimoniales, al servicio de su beneficio. Como consecuencia de la profunda insensibilidad ética que define a las sociedades corruptas, la tolerancia con la trasgresión de la ley moral y positiva es muy alta.

La situación resultante es realmente compleja, por estar sujeta a un doble círculo vicioso: como subraya Francisco Miró Quesada Rada, la corrupción aumenta el desprestigio de la política, lo cual reduce el interés del ciudadano por los asuntos públicos. Y esa desatención por lo público, a su vez, relaja el control de los representados sobre los representantes, favoreciendo la corrupción. Por otro lado, la dimensión sistémica de la corrupción se lo pone muy difícil a aquellos ciudadanos que quieran actuar de forma virtuosa, porque al optar por servir al interés general a título individual, se encontrarán en una situación de desventaja competitiva respecto de sus conciudadanos egoístas.

A pesar de la distancia que separa nuestras sociedades de la justicia social, el libro evita el tono pesimista y fatalista. Gonçal Mayos Solsona se mueve en esa dirección cuando recuerda que vivir en un momento de confrontación social, política y económica también significa vivir el momento decisivo en el que se 
asientan las bases sobre las cuales se definirá la política posible y la gobernanza mundial en los próximos años. En nuestro presente descansa la posibilidad de deshacernos de todo lo viejo y obsoleto, y de acelerar la llegada de lo nuevo. Y, con Ricardo Velázquez Ramírez, la identificación de las debilidades de los sistemas políticos vigentes que se lleva a cabo en este libro resulta fundamental para poder diseñar medidas que superen esas debilidades, aprovechando la ventana de oportunidad que se abre ante nosotros para salir de esta crisis con una democracia y una ciudadanía reforzada. La ciudadanía y lo político. Ciudadanía y crisis de la democracia liberal en un mundo en transformación supone un paso más en esta dirección, y por ello no queda más que felicitar a sus autores por sus aportaciones, y a Joan Lara Amat y León por su labor como editor. Quedamos a la espera de nuevas contribuciones de este prometedor proyecto. 